\title{
LA VIÑA DE NABOT, SUS DIVERSAS LECTURAS Y EL (AB)USO DE PODER DE UNA REINA
}

\section{Resumen}

La apropiación de la viña de Nabot plantea numerosas pistas hermenéuticas, en especial desde una lectura latinoamericana y feminista. A pesar de que el capítulo no es neutral, puesto que la palabra final la tienen YHWH y su profeta Elías (y, si miramos 2 Re 9, también el grupo jehuíta justificando su golpe de Estado y los redactores deuteronomistas, constatando el cumplimiento del oráculo de Elías contra Ajab, Jezabel y su dinastía, 2 Re 21,1729), diversos estudios diacrónicos y sincrónicos del capítulo muestran una vez más que un texto nunca muere, siempre tiene una reserva de sentido. En esta contribución se presentan algunos de los resultados, diametralmente opuestos entre sí, de estudios de 1 Re 21: lecturas que condenan a ambos gobernantes; lecturas que afirman la legalidad de lo ejecutado; lecturas que exploran las aristas jurídicas con apoyo en fuentes del antiguo Oriente; lecturas que resaltan la agencia de Jezabel, el deseo de Ajab, el cambio drástico en la suerte de Nabot o la intención abortada de YHWH de quitar la vida a Ajab de inmediato. Como buena parábola o historia, nos involucra en situaciones social, política y jurídicamente complejas, donde el género (tanto en la construcción del texto mismo de sus personajes como en la lente de la estudiosa) también contribuye a complejizar, fijándose en la mujer en el poder político.

Palabras clave: Ajab. Jezabel. Viña de Nabot. Lecturas diacrónica, sincrónica y sociopolítica. Lectura de género.

En el célebre episodio de la viña de Nabot, el profeta desenmascara la injusticia de Ajab y Jezabel contra el derecho de un israelita (1 Re 21), como antes Natán había enfrentado a David a causa del asesinato de Urías. Es decir, que los profetas actuaron en un marco político y social bien determinado y que no permanecieron ajenos a los desafíos que les planteaba su inserción en esa realidad ${ }^{1}$.

1 A. J. LeVoratti, “La lectura 'política’ de la Biblia”, Teología XXIII, 48 (1986) 5-43 (26). 
La arbitrariedad de reyes como Ajab es uno de los ejemplos preferidos para una lectura de textos que claramente se enmarcan en un contexto político en los antiguos Israel o Judá. Pero también hay una segunda clase de lectura política, que se realiza "sobre todo en sentido subjetivo, en cuanto la política se constituye en sujeto hermenéutico, en principio y criterio de la comprensión e interpretación de los textos" ${ }^{2}$. Lo que nuestro homenajeado escribía en 1986, apuntando a una gran fuerza positiva, se ha ido concretando en nuestro continente en diversas formas de la teología de la liberación, como teologías feministas, negras, aborígenes, poscoloniales, queer y otras. Ese itinerario, de una lectura identificadora de textos relacionados con lo político a una lectura hermenéutica que impugne cualquier opresión sociopolítica, ha sido el itinerario de las lecturas de género y feminista, desde identificar a mujeres importantes en ciertos textos bíblicos, para crear conciencia de su existencia, hasta leer cualquier texto desde la crítica de género. Ofrezco estas páginas agradecida por ser parte de este homenaje a un colega biblista, cuya presencia honró mi instalación como clérigo en la Iglesia Evangélica Luterana en La Plata ya en 1986 y quien también me invitó a ser parte de su equipo de traducción; ha sido siempre agradable trabajar con usted, Padre Armando.

La presente reflexión busca poner en diálogo varias lecturas practicadas sobre un mismo texto, muy interesantes y casi todas inaccesibles en castellano. Por una parte, 1 Re 21 contiene la denuncia profética de Elías el tisbita contra la violencia monárquica ejercida por Ajab y Jezabel, de tono similar a la del profeta Natán ante el adulterio (y probable violación, dado el desbalance de poder y la falta de consentimiento de ella) con Betsabé y el asesinato de Urías por parte de David (2 Sam 11). Por otra parte, es posible también hacer una lectura igualmente cuidadosa del texto que defienda las acciones de Jezabel y los ancianos y muestre a Nabot condenado con justicia por haber pronunciado un anatema contra su rey. Asimismo, se puede leer el texto como una parábola sobre la viña y la huerta, un Israel floreciente y uno en esclavitud, y con muchas otras claves. Como todo buen texto, ofrece una variedad de posibilidades hermenéuticas e invita a releerlo siempre con nuevos ojos, dadas las cambiantes preocupaciones sociales, teológicas y pastorales. En la próxima sección resumiré algunas de estas propuestas, organizándolas a partir de los métodos o enfoques utilizados para su estudio (diacrónicos, sincrónicos, jurídicos y otros). En lo posible pondré la lente sobre la reina Jezabel, una de las mujeres más despreciadas de la Biblia hasta nuestros días. Sin embargo, lo que presento no es un estudio sobre Jeza-

2 Ib., 38-39. 
bel, puesto que apenas mencionaré su desenlace en 2 Re 9, donde el Deuteronomista (Dtr) elabora un pesado escenario de idolatría y muerte ${ }^{3}$.

$\mathrm{Al}$ comenzar a leer nuestro texto descubrimos que, con la excepción de Nabot el jezreelita, cada protagonista fue presentado anteriormente. El primero que aparece es Ajab, a la manera Dtr de presentar a los reyes. Ajab tiene patronímico (aunque sin mencionar madre), a diferencia de Nabot y de Elías, de quienes solamente se consigna su gentilicio. De Ajab nada bueno se dice:

Ajab, hijo de Omrí, comenzó a reinar sobre Israel el trigésimoctavo año de Asá, rey de Judá, y reinó sobre Israel, en Samaría, durante veintidós años. Ajab, hijo de Omrí, hizo lo que es malo a los ojos de YHWH, más que todos sus predecesores. Y, como si no le hubiera bastado persistir en los pecados de Jeroboán, hijo de Nebat, tomó por esposa a Jezabel, hija de Etbaal, rey de los sidonios, y fue a servir a Baal y se postró delante de él. Erigió además un altar a Baal en el templo que le había construido en Samaría. Ajab hizo también el Poste sagrado, y continuó provocando la indignación de YHWH, el Dios de Israel, más que todos los reyes que lo habían precedido (1 Re 16,29-33) ${ }^{4}$.

Esta introducción de Ajab es también la presentación de Jezabel: "Tomada para esposa de" e "hija de" son sus primeras caracterizaciones, que intentan quitarle agencia propia. Además, indirectamente, se la responsabiliza del desvío de Ajab hacia Baal, un motivo típico Dtr. Varios/as estudiosos/as señalan con razón que la evidencia bíblica indica que Ajab fue respetuoso de YHWH y de sus profetas. Por ejemplo, sus hijos Ocozías יורם עת A עליהו עזיהו, si es que es hija y no hermana de Ajab) tienen nombres yahvistas; y la reacción de Ajab ante palabras proféticas adversas no es matar al mensajero, sino irse a su casa enojado y resentido ${ }^{5}$.

3 Al respecto, véase M. MEnA LóPEz, “Comerán los perros la carne de Jezabel: sexo e idolatría, metáforas que legitiman la muerte de extranjeros", RIBLA 41 (2002) 58-63. Más brevemente (pero con interesantes reacciones de lectores/as), J. Howe GaInEs, “How Bad Was Jezebel?", Bible History Daily (junio 2010), en http:// www.biblicalarchaeology.org/daily/people-cultures-in-the-bible/people-in-the-bible/how-bad-was-jezebel/ [consulta: 12/7/16].

${ }^{4}$ Las citas bíblicas están tomadas de La Biblia: Libro del Pueblo de Dios, Estella 2015, reemplazando "el Señor" por "YHWH".

${ }^{5}$ F. C. YAFÉ, Profetas, reyes y hacendados. Estudio teológico-sociológico y crítico del Israel preclásico, Buenos Aires 1997, 84; LEE, “Königsbücher”, 139, nota que, a partir de esta época, ambos reinos comienzan a tener soberanos con nombres yahvistas. F. R. Magdalene, "Trying the Crime of Abuse of Royal Authority in the Divine Courtroom and the Incident of Naboth's Vineyard", en A. Mermelstein - Sh. E. Holtz (eds.), The Divine Courtroom in Comparative Perspective, Leiden 2014, 167-245 (203204), nota un comportamiento similar de Ajab en la historia de 1 Re 20,38-42. Agradezco a la autora el envío del artículo. 
Confinando al rey en una inclusio de acusación, los Deuteronomistas citan como su maldad primaria su casamiento con esta extranjera. "Y [Ajab] tomó por mujer a Jezabel, la hija de Etbaal, rey de los sidonios" (1 Re 16,31). Rodeada por los sustantivos "esposa" e "hija", Jezabel entra a Israel por un acuerdo entre varones. Esposo y padre la definen. Además, el deletreo fecal de su nombre, apuntado en el hebreo para producir el significado pervertido de "estiércol", muestra total desprecio, al tiempo que presagia su eventual final. Ninguna mujer Ini varón) en las Escrituras hebreas sufre prensa tan hostil como Jezabel.

No sorprende que la hostilidad se centre en su afiliación religiosab.

Además es extranjera. Y, aunque es hija del rey de una potencia (no hay madre mencionada), y por tanto criada en un ámbito de élite, educada, presumiblemente acostumbrada a manejarse en el poder, nunca se la llama princesa ni reina. Las referencias se contentan con su nombre de pila o una relación familiar: "su esposa" (p. ej. 2 Re 21,25), "tu madre" (2 Re 9,22). En 2 Re 10,13 es "la reina madre", aunque todavía relacionada con sus hijos ${ }^{7}$. Dado que, de las múltiples esposas de Ajab (2 Re 10,1 le atribuye el paradigmático número de setenta hijos en Samaría), la única identificada en toda la Biblia es Jezabel, podemos suponer un vínculo entre ambos de influencia y cercanía. Esta comunicación conyugal tan fluida no es común en la Biblia, como ha notado Helena Zlotnick: en toda la Biblia hebrea presenciamos la comunicación directa entre cónyuges reales (en los cuales la esposa habla libremente con su esposo rey) de tres mujeres solamente: Betsabé con David, Jezabel con Ajab y Ester con Asuero ${ }^{8}$.

6 Ph. Trible, “Exegesis for Storytellers and Other Strangers”, JBL 114 (1995) 3-19 (3-4). Mena López, 59. y Cl. Camp, "1 and 2 Kings", en C. A. Newsom - Sh. H. Ringe (eds.), The Women's Bible Commentary, Louisville 1992, 96-109 (103), dudan también de que existiera una persecución a los profetas yahvistas, dado el politeísmo de Jezabel; sería, más probablemente, una persecución política.

7 Irónicamente son los cuarenta y dos hermanos de Ocozías, el rey de Judá, quienes le dan el título de גבירה a Jezabel cuando se encuentran con Jehú. CAMP, 98 conjetura que la autoridad de las reinas madres puede haber surgido de su papel en el culto a Aserá; cf. Z. BEN-BARAK, "The Status and Right of the Gĕbîrâ", JBL 110 (1991) 23-34; S. ACKERMAN, "The Queen Mother and the Cult in Ancient Israel", JBL 112 (1993) 385-401; J. F. PARKER, “'Queens' and Other Female Characters: Feminist Interpretations of First and Second Kings", en S. Scholz (ed.), Feminist Interpretation of the Hebrew Bible in Retrospect, I: Biblical Books (Recent Research in Biblical Studies 5), Sheffield 2013, 135-149 (137-139 y bibliografía en 138, n. 9). Sobre la imagen de la mujer asomada a una ventana representando a una reina o una diosa: N. Aschkenasy, Woman at the Window: Biblical Tales of Oppression and Escape, Detroit 1998; E. Ferris BEACH, “The Samaria Ivories, Marzeah, and Biblical Text”, BA 52 (1993) 94-104; J. Everhard, “Jezebel: Framed by Eunuchs?”, CBQ 72 (2010) 690-692.

${ }^{8} \mathrm{H}$. ZlotNIK, "From Jezabel to Esther: Fashioning Images of Queenship in the Hebrew Bible", Biblica 82 (2001) 477-495 (479), en http://www.bsw.org/biblica/vol- 
Jezabel es una esposa de carácter fuerte que quizá despreciara a un esposo "blando" con sus súbditos (o que no comprendiera un modelo más igualitario entre gobernantes y gobernados), pero que se esfuerza por darle a Ajab lo que este desea, como buena esposa. Este no es un punto menor, dada su extendida fama como promiscua. Sin embargo, nada en la Biblia hebrea apunta a tal característica, excepto la típica frase Dtr de Jehú en 2 Re 9,22, "las prostituciones de tu madre Jezabel y sus innumerables brujerías", poniendo ambas conductas en paralelo, כשפיה הרבים yנוני איזבל אמך. Sin embargo, la raíz זנה frecuentemente indica "ir tras otras divinidades", no una conducta sexual independiente (por ejemplo Is 1,21); acepción que cuadra mucho mejor a la imagen jezabelita transmitida por Dtr que la de promiscuidad ${ }^{9}$.

Nabot es un personaje misterioso en muchos sentidos. Su nombre no tiene significado aparente y se lo relaciona en términos muy generales con Jezreel, un valle asignado a la tribu de Isacar (Jos 19,18), que sería su lugar de nacimiento ${ }^{10}$. Es mencionado solamente en $1 \operatorname{Re} 21$ y $2 \operatorname{Re} 9,21-26$. La falta de patronímico de Nabot podría indicar una situación anómala con respecto a su linaje, lo que explicaría su énfasis en su tierra como "heredad de mis padres"; pero el texto evita entrar en detalles al respecto ${ }^{11}$. Si bien ignoramos las dimensiones de su viñedo y de su riqueza, gobernaba a las puertas con los ancianos y nobles (v. 8), lo cual indica una posición de solidez social, económica y política. 2 Re 9 lo hace dueño de un campo (¿la viña convertida en huerta?) y padre de hijos, también muertos. No hay ma-

82-2001/from-jezebel-to-esther-fashioning-images-of-queenship-in-the-hebrew-bible/271/article-p479.html [consulta: 20/3/2016], plantea la historia de Ester como una versión reversible del ciclo de Jezabel; por ejemplo, el uso del sello real es a favor del pueblo (judío) y no para beneficio personal. Queda pendiente un análisis de las similitudes y diferencias de las tres historias (por ejemplo, Natán y Elías juegan papeles similares de acusación al rey por sus crímenes, mientras en Ester no hay un profeta presente; David y Ajab pertenecen a Israel, pero Mardoqueo no; Ester es judía, Jezabel es fenicia y Betsabé es esposa de un hitita (sin nacionalidad propia).

9 Everhard, “Jezebel: Framed by Eunuchs?”, 688-698 (688 n. 2): “El uso de “jezabel' como sustantivo, definido por el diccionario Merriam-Webster (11 a edición) como 'una mujer impúdica, sin vergüenza o moralmente desenfrenada' indica la constante influencia de las interpretaciones bíblicas en la sociedad moderna".

10 N. NA'AMAN, “Naboth's Vineyard and the Foundation of Jezreel”, JSOT 33 (2008) 197-218 (204).

11 En general, los extranjeros son identificados por su gentilicio, como Urías el hitita. Sin embargo, quizá la razón fundamental para esta falta de patronímico no esté ligada a la tierra, sino al carácter parabólico del texto, al modo de Job del país de Us (Job 1,1) o Lemuel, rey de Massá $(\operatorname{Pr} 31,1)$, imposibles de identificar. 
dre, esposa ni hijas. Su juramento de que "YHWH prohíbe" su venta lo muestra observante de lo que él interpreta como palabra divina.

En cuanto a Elías, aparece de la nada, sin linaje, infancia ni vocación profética en 1 Re 17,1, después de la presentación de Ajab y de Jezabel. De la misma manera aparece en la segunda mitad de nuestro texto por orden divina, sin anuncio previo, desapareciendo al final sin contestar la pregunta (posiblemente retórica) de $\mathrm{YHWH}^{12}$. No transmite el anuncio de $\mathrm{YHWH}$ en forma textual ni en sus palabras ni al agregar a Jezabel en su acusación.

Un elemento clave en la lectura es la tensión entre un modelo relacionado con las prácticas agrícolas tradicionales, encarnado en Nabot y en Elías, y otro modelo centrado en la ciudad y la diplomacia internacional, encarnado en Ajab y en Jezabel. Mientras que Nabot tiene y atesora una viña, la cual requiere unos años de trabajo para producir fruto, Ajab quiere comprarla para convertirla en una huerta. El término que usa es גן ירק. En la Biblia hay varios espacios llamados גן, comenzando por el de Edén (Gn 2,8-10.15-16). Pero la misma combinación, גירק más, aparece solamente en referencia a las huertas de la esclavitud:

Porque la tierra que tú vas a tomar en posesión no es como Egipto, el país de donde ustedes salieron. Allí sembrabas tu semilla y luego tenías que regar con tu pie, como se riega una huerta. En cambio, la tierra que vas a tomar en posesión es una región de montañas y valles regados por la lluvia del cielo, y está bajo el cuidado constante de YнwH, tu Dios. Sobre ella permanecen fijos los ojos de YHWH, tu Dios, desde el comienzo hasta el fin del año (Dt 11,10-12) ${ }^{13}$.

Una viña requiere muy poca agua para mantenerse, mientras que una huerta de vegetales consumiría una cantidad mucho mayor (como lo indica el mismo texto recién citado). Por otra parte, en el contexto de la sequía anunciada por Elías, las prioridades de Ajab y de Jezabel muestran que se identifican con el palacio: los cuatrocientos cincuenta profetas de Baal (sin contar los cuatrocientos de Aserá, 1 Re 18,19), a quienes Jezabel alimentaba diariamente, mientras Elías es alimentado por una viuda en Sarepta (1 Re 17,7-16), y entre tanto Ajab busca pasto para sus animales (1

12 Este recurso de dejar abierta la pregunta final es típico de narraciones ficticias como las parábolas, cf., por ejemplo, la del “buen samaritano" (Lc 10,36, aunque en este caso sigue una respuesta del jurista), el final de Jonás y aun el final del diálogo en Gn 34 entre Jacob y los hermanos de Dina.

13 Notado por S. WelLS, "Nahoth's vineyard, and God's justice: Forgiving Ahab", Christian Century 17/4 (2013) 32-34 (33). “Así que el deseo de Ajab de convertir la viña de Nabot en una huerta hortícola es un símbolo de la intención de Ajab de llevar a Israel de nuevo a la condición de esclavitud en Egipto" (33). El término ירק aparece en $\operatorname{Pr} 15,17 ;$ y en $2 \operatorname{Re} 19,26$ e Is 37,27 aparece ירקדשט, "hierba verde". 
Re 18,5$)^{14}$. En un mundo donde el agua es un bien muy escaso (y donde obtenerla o no significa la vida o la muerte), estos datos del texto no son menores.

Hecha esta introducción de los personajes principales de nuestra historia, a continuación revisaré algunas de sus lecturas.

\section{Lecturas sincrónicas, lecturas diacrónicas, lecturas diversas}

1 Re 21 es una historia que comienza con un rey, Ajab, deseando comprar o permutar a Nabot su viña, cuyo desarrollo se resuelve en el v. 16: "Sucedió que, al oír Ajab que Nabot había muerto, se levantó Ajab para descender a la viña de Nabot el jezreelita para tomar posesión de ella". Narrativamente es el final del argumento: Ajab ofreció comprarla, Nabot se negó, Nabot fue juzgado, Nabot ya no vive, Ajab tomó posesión de la viña que deseaba. Fin de la historia... Pero en el v. 17 irrumpe la palabra de YHWH, por lo cual podemos imaginarnos que el fin de la historia no es el fin. YHWH envía a su profeta, Elías el tisbita, a anunciar un oráculo de castigo a Ajab por haberse "vendido haciendo el mal a los ojos de YHWH" (v. 20). En este momento baste notar que Elías no transmite las palabras que YHWH le encomendara, “¿mataste y además expropiaste?”, sino que lo acusa en términos muy generales de "hacer lo malo ante YнWH". A continuación, Elías le anuncia que el castigo involucra también a su esposa e instigadora Jezabel y a todo varón de su descendencia. Sin embargo, la razón ha pasado a ser la idolatría, no el asesinato o la posesión ilegal de un terreno. Sea como fuere, Ajab se arrepiente y YHWH posterga la pena de muerte, conmutándola por la muerte de su descendencia.

Hay diversas versiones del cumplimiento (parcial o modificado) de este oráculo: en el siguiente capítulo, Ajab muere sobre su carro, pero es trasladado a Samaría, donde es enterrado (1 Re 22,37-40), por lo cual el anuncio de que los perros lamerían su sangre en la misma ubicación geográfica donde murió Nabot se realizó solo parcialmente. Su hijo mayor y sucesor, Ocozías, muere después de que Elías le indicara que no sobreviviría a una caída de una ventana ( 2 Re 1$)$; pero allí no hay referencia al epi-

14 Magdalene, 208 encuentra a Ajab poco inteligente, ya que "reemplazar un viñedo productivo por una huerta personal de verduras" es "una decisión económicamente muy pobre". 
sodio de Nabot como explicación por su muerte. Más tarde, Jehú es ungido rey de Israel por "uno de los profetas" enviado por el mismo Elías y termina con la "casa de Ajab" asesinando a Jorán (por entonces recuperándose de heridas de guerra en Jezreel) y a Jezabel, reina madre, apostada en lo alto (de una torre o palacio, el escenario no está especificado, cf. 2 Re 9,30). Después de asesinar a Jorán, Jehú ordena a su escudero que arroje el cuerpo de Jezabel en el campo de Nabot, justificándose en el cumplimiento de esta profecía (nótese de paso cómo involucra a Bidcar como testigo de la profecía):

Entonces Jehú dijo a Bidcar, su escudero: “Levántalo y arrójalo en la parcela del campo de Nabot el izreelita. Acuérdate de que cuando tú y yo cabalgábamos a la par, detrás de su padre Ajab, YHWH pronunció contra él esta sentencia:

¿No he visto ayer la sangre de Nabot

y la sangre de sus hijos? -oráculo de YHWH -.

Yo te daré tu merecido

en este mismo campo -oráculo de YHWH -.

Ahora, levántalo y arrójalo en esta parcela, conforme a la palabra de ҮнWH" $(2 \operatorname{Re} 9,25-26)^{15}$.

Desde el análisis histórico-crítico, estas diferencias entre la expropiación de la viña y los oráculos de cumplimiento se explican como estratos redaccionales. Hay una opinión generalizada de que el episodio de la viña habría ocurrido durante el reinado de Ajab o unas décadas más tarde. Ante la evidencia posevento de que la manera de las muertes de Ajab y de Jezabel y sus hijos no concordaba con este primer oráculo, fueron agregados los vv. 27-29 (y porciones de $2 \mathrm{Re})^{16}$. Un estudio de las fuentes y de la

15 I. FinkelsteIn, The Forgotten Kingdom: The Archaeology and History of Northern Israel, Atlanta 2013, 85, toma este episodio como un ejemplo paradigmático de la disonancia entre el texto bíblico y la arqueología: "En 2 Re 9 leemos que los dos reyes [Jorán de Israel y Ajacías de Judá] fueron muertos en el transcurso de la revuelta de Jehú, mientras que, en la estela de Tel Dan, Jazael [de Damasco] se atribuye este evento".

16 D. Pruin, “What Is in a Text? Searching for Jezebel”, en L. L. Grabbe (ed.), Ahab Agonistes: The Rise and Fall of the Omri Dynasty, Londres 2007, 208-235 (212), data nuestra historia en los siglos VIII a vII antes de la era común, debido a que "[la] narración trata sobre el resquebrajamiento de la comunidad jurídica. Acusa a la pareja gobernante Ajab y Jezabel de abusar de sus poderes reales y de la ley. Además, la narración acusa a los nobles de la ciudad de Jezreel de apoyar la conducta malvada y así dejar de ser una comunidad jurídica. Contrastando con el oráculo anónimo de juicio en 2 Re 9.26a, ahora es Elías el que critica al gobernante omrida". M. A. SweEney, I \& I/ Kings (Old Testament Library), Louisville 2007, 330-331, calcula que esta historia se agregó al ciclo de Elías-Eliseo en la primera mitad del 
redacción de 1 Re 21 y pasajes de 2 Re hecha por Patrick Cronauer, sin embargo, llega a resultados opuestos. Para él, "1 Re 21,17a a-19a $\beta$ y 20a $\alpha$-Ba" (en términos generales, el envío por parte de YHWH de Elías a acusar a Ajab de haber asesinado y expropiado) serían parte de "un antiguo fragmento sobre Elías y Nabot" ${ }^{17}$, lo más antiguo del relato, reelaborado posteriormente mediante diversos recursos, tales como constataciones de cumplimiento de una justicia retributiva (p. e., el oráculo de 2 Re 9,25-26), oráculos de transferencia del castigo y redacción anti-Jezabel. Para este autor, los vv. 1-16 son muy posteriores al oráculo, de "algún momento durante el período persa, de fines del siglo vi al IV a.e.c." ${ }^{18}$. Cronauer se basa también en semejanzas lingüísticas con textos tardíos como los de Esdras y Nehemías ${ }^{19}$, sobre

siglo VIII a.e.c., cuando la dinastía jehuita se aseguró bajo Joás ben Yehoahaz y Jeroboán ben Joás (2 Re 14). NA'AMAN, 206 coincide en fecharla en la misma época de la historia del golpe de Estado de Jehú, por tener en común estos elementos: “(1) la centralidad de Jezreel en tiempo de los omridas; (2) la ubicación de una residencia real en la ciudad; (3) el viaje de la familia real al lugar; (4) la vecindad de la residencia real al viñedo/campo de Nabot". Por su parte, basándose en el principio de la ley del talión, MagdaLENE, 227-228 considera que del anuncio de Elías del castigo a Ajab sabemos más detalles de la suerte que corrieron Nabot y sus hijos.

17 P. T. Cronauer, The Stories about Naboth the Jezreelite. A Source, Composition, and Redaction Investigation of 1 Kings 21 and Passages in 2 Kings 9, New York 2005, 7. Cf. NA'AMAN, 200, considerando la historia original, "los vv. l-20ba Imenos breves glosas editoriales)", a los que el Deuteronomista agregó los “vv. 20by-24, 27-29 y lo combinó con la obra anterior [...] Para combinar su texto con la historia original acortó el final de esta historia, y no hay manera de reconstruirla".

18 Cronauer, 185. Su estudio ha recibido algunos cuestionamientos que no hacen al meollo de nuestra cuestión, pero que se deben consignar. Por ejemplo, R. F. PERSON, Jr.. recensión de P. T. Cronauer, The Stories about Naboth the Jezreelite, en CBQ 68 (2006) 726-727, cuestiona una terminología concerniente a las diversas redacciones deuteronomísticas poco cuidadosa en cuanto a definiciones y fechas; H. S. PYPER, recensión de Patrick T. Cronauer, The Stories about Naboth the Jezreelite, en JSOT 30.5 (2006) 66-67, cuestiona la propuesta de que 1 Re 21,1-16 contenga elementos “implícitos" en los vv. 17-19 (p. 108 de Croanauer), pero concluye que "ofrece mucho para seguir pensando y un análisis cuidadoso del texto en el trabajo de C., que recompensará al(la) lector(a)" (67); y H. G. M. WiLliamson, recensión de P. T. Cronauer, The Stories about Naboth the Jezreelite, en VT 57 (2007) 127, también concluye: “Aunque la especificidad de sus propuestas significa que comentaristas posteriores podrán disputar detalles individuales, la dirección general de su argumento parece convincente..."

19 Cronauer, 182-185. Cf. también A. Rofé, “The Vineyard of Naboth: The Origin and Message of the Story", VT 38 (1988) 89-104 (102), sobre la cercanía ideológica de esta historia con la política de Esdras y Nehemías acerca de matrimonios con extranjeras y sobre la crítica a la opresión de las clases altas, que comparte con "Nehemías, Malaquías y Trito-Isaías". 
la utilización de vocabulario considerado posexílico y sobre la semejanza estructural de nuestra historia con la de la apropiación davídica de Betsabé $^{20}$. La propuesta de Cronauer involucra una mirada particular sobre Jezabel, así como sobre un período de la historia bíblica particularmente agresivo para con las mujeres extranjeras, puesto que el origen de la historia -que además él considera una parábola- no es un evento verídico de una reina despótica y asesina, sino un ejercicio de escribas con una finalidad pedagógica.

Simon DeVries interpreta la historia dentro del subgénero de la "narrativa real de autoincriminación, tipo 2, historia de acción abusiva", a la manera de la desobediencia de Saúl al mandato de eliminar a cada amalecita con sus posesiones (1 Sam 15,1-35) o su consulta a una médium (1 Sam 28,4-25 ${ }^{21}$. Como lamentablemente no tuve acceso a este estudio más abarcativo de De Vries no puedo sacar consecuencias posteriores de su descubrimiento de que se trata de una narrativa de autoincriminación, pero no parece exagerado imaginar una intención didáctica en la historia.

Por su parte, Marvin Sweeney separa todo el texto en tres subunidades, usando a Ajab y su rol central como criterio de clasificación:

La estructura de la narración está basada sobre una presentación de los caracteres principales que interactúan con Ajab. Así, la primera subunidad, en los vv. 1-4, nombra a Nabot en el v. 1aB, quien declina la oferta de Ajab de comprar su viñedo. La segunda, en los vv. 5-16, nombra a Jezabel, la cual primero pregunta por la causa del malhumor de Ajab y después toma medidas para conseguir la viña, acusando falsamente a Nabot. La tercera, en los vv. 17-29, nombra a Elías hablando de parte de YHWH, quien condena a Ajab y su casa por el asesinato ${ }^{22}$.

Enseguida veremos que hay elementos adicionales que permiten subdividir esta estructura básica en una más compleja. Sin embargo, Sweeney ha percibido la importancia de Ajab y su deseo en esta historia. Una lectura estructural del relato (como la practicada por Jerome Walsh) confirma esta intuición, que a continuación resumiré. Walsh desea mostrar cómo la elección de una metodología determinada influye en la lectura, y para eso aplica a $1 \operatorname{Re} 21$ tres análisis sincrónicos, que él denomina "análisis es-

20 Cronauer, 190-191. Sobre semejanzas con la historia de David-Urías-Betsabé, NA'AMAN, 207, n. 8.

21 S. J. DeVRIES, 1 Kings (Word Biblical Commentary), Waco 1985, 255, en referencia a su libro Prophet against Prophet: The Role of the Micaiah Narrative (1 Kings 22) in the Development of Early Prophetic Tradition, Grand Rapids 1978, 90, 115-116, 130 132.

22 SWEENEY, 247. 
tilístico", "análisis sintagmático" y "análisis programático"23. La terminología de Walsh no se ha popularizado, de modo que requiere una corta explicación. Por "análisis sintagmático" se refiere a un análisis estructural que evalúa el movimiento narrativo de cada parte (vv. 1-16 y 17-29). Cada parte de la historia comienza con una situación de equilibrio (Nabot tiene una viña, Ajab está condenado a muerte), surge un elemento desequilibrante mediante mensajes (de Jezabel en nombre de Ajab y de Elías en nombre de YHWH), para cerrar con una nueva situación de equilibrio: Nabot perdió su viña y su vida, Ajab "recuperó" su vida. En ambos casos hay agentes de equilibrio, leyes (que serían aplicadas tanto en la negativa de Nabot como en el "ojo por ojo" de la muerte de Ajab en la propiedad de Nabot) y ayunos (uno, de los ancianos de Jezreel; otro, sincero, por parte de Ajab, que permite que se posponga su sentencia de muerte).

\section{Cuadro 1: Lectura sintagmática}

\begin{tabular}{|l|l|l|}
\hline vv.1-16 & vv. 17-29 \\
\hline $\begin{array}{l}\text { Nabot tiene una viña, } \\
\text { heredada de sus padres }\end{array}$ & $\begin{array}{l}\text { situación inicial de } \\
\text { equilibrio }\end{array}$ & Ajab condenado a muerte \\
\hline $\begin{array}{l}\text { ley de no alienación del } \\
\text { patrimonio }\end{array}$ & base del equilibrio & ley del talión \\
\hline $\begin{array}{l}\text { Jezabel (mensaje escrito en } \\
\text { nombre de Ajab) }\end{array}$ & agente de desequilibrio & $\begin{array}{l}\text { Elías (mensaje oral en } \\
\text { nombre de YHWH) }\end{array}$ \\
\hline ayuno hipócrita y penitencia & base del nuevo equilibrio & ayuno sincero y penitencia \\
\hline Nabot pierde viña y vida & situación final de equilibrio & $\begin{array}{l}\text { a Ajab se le perdona la vida; } \\
\text { "pasa" muerte a hijos }\end{array}$ \\
\hline
\end{tabular}

Esta lectura es importante para nuestro análisis, pues muestra que Jezabel y Elías cumplen igual rol, lo cual se confirma con una lectura más amplia del ciclo de Elías, en particular del evento en el monte Carmelo (1 Re 17-19) ${ }^{25}$. No es un descubrimiento nuevo que estos dos titanes estén

23 J. T. WALSH, "Methods and meanings: Multiple studies of 1 Kings 21", JBL 111 (1992) 193-211.

24 WALSH, 202-203.

25 WALSH, 205-208; cf. recuadros semióticos sobre comer - no comer - ser comido - no ser comido para Ajab y Nabot en 207-208, que merecen ser retomados y ampliados con los (supuestos) cumplimientos de estos oráculos proféticos en $2 \mathrm{Re}$ 9-10 lallí se retoma el tema del comer de Jehú y ser comida de Jezabel, que Walsh no lo trabaja por restringirse (con buen criterio) a 1 Re 21. 
ligados por múltiples caracterizaciones: Phyllis Trible, una pionera en la lectura feminista, la llamó "una pareja extraña" ${ }^{26}$. Por su parte, Stephanie Wyatt amplía el análisis: "Ambos personajes se encuentran en esta frase [agregada en la versión griega de 1 Re 19,2: "Si vos sos Elías, entonces yo soy Jezabel"], así como los dioses a quienes sirven se entremezclan. El nombre de Jezabel es heraldo de Baal (“¿Dónde está el príncipe?’) y el de Elías proclama su divina lealtad ('YHWH es mi Dios')" 27.

Volviendo a Walsh, veamos brevemente lo que él llama "análisis paradigmático", más conocido, a partir de los estudios semióticos, como modelo actancial. Aquí se percibe que el deseo de Ajab de adquirir la viña de Nabot tiene como sujeto actante a Jezabel, mientras que los ancianos de Jezreel, los testigos indignos y la asamblea que lo enjuicia son actantes coadyuvantes. Se oponen a Ajab el mismo Nabot y una aparente ley de patrimonio (que no conocemos en el relato). Esto en cuanto a la primera parte, mientras que en la segunda parte Elías es el sujeto de la muerte de Ajab, ordenada por YHWH y opuesta por el arrepentimiento del mismo Ajab. Es notable que, en este último modelo, el actante opositor, Ajab, se sobreponga al actante emisor, YHWH, al ser transferida su pena de muerte a su descendencia.

Nos queda por repasar el análisis estilístico de Walsh. Este demuestra una estructura doble, donde cada parte está a la vez armada como estructura concéntrica de seis escenas, A, B, C, C', B' y A' (cf. el cuadro 2). Las escenas I.A y I.A' suceden en la viña entre Ajab y Nabot y Ajab y Elías; las escenas I.B y I.B' suceden en el dormitorio de Ajab. El centro (I.C y I.C') está en los vv. 8-10 y 11-14, y concierne las instrucciones de Jezabel para llevar adelante el juicio a Nabot y el reporte a ella de su ejecución. En estos primeros dieciséis versículos, Jezabel es el personaje central. Además de participar o ser nombrada en varias de las escenas, es

26 Ph. Trible, “The Odd Couple: Elijah and Jezebel”, en Ch. Büchmann - C. Spiegel (eds.), Out of the Garden: Women Writers on the Bible, New York 1994, 166-179 (178), inaccesible para mí; citado por St. WYATT, “Jezebel, Elijah, and the Widow of Zarephath: A ménage-à-trois that Estranges the Holy and Makes the Holy the Strange", JSOT 36 (2012) 435-458 (436).

27 WyATT, 456. Wyatt incorpora una tercera figura, la de la viuda de Sarepta, para quebrar la dicotomía y mostrar las ambigüedades de cada personaje en cuanto a origen y relación con su respectivo Dios. Ella muestra, por ejemplo (444-446), que el origen mismo del profeta es ambiguo, dado que es el único tisbita y que su primera presentación en 1 Re 17,1 está asociada a los residentes temporarios (heb. tôšāb) de Galaad, sin patronímico. Sobre el nombre Jezabel, cf. R. Jost, “Isebel”, https://www. bibelwissenschaft.de/wibilex/das-bibellexikon/lexikon/sachwort/anzeigen/details/ isebel-1/ch/9059fc253174a27436f7b3b79d34cb73/ [consulta: 20/3/16]. 
el agente clave para el desarrollo de la acción. No solamente esto: las escenas I.B' y I.A' (vv. 15 y 16) dan mucho más espacio a las palabras de Jezabel que a las acciones de Ajab, cuyas palabras, contrarias a la costumbre bíblica de citar a varones mucho más que a mujeres, no son consignadas $^{28}$.

Más allá de su protagonismo, muchos comentarios se han preguntado por la verosimilitud jurídica de todo el proceso, con respuestas divergentes. Hay al menos "siete posiciones principales entre quienes argumentan que Nabot no podía vender su tierra y tres posiciones principales (con seis subtipos) entre quienes arguyen que Nabot no quería vender su tierra" ${ }^{29}$. Es posible que a lo largo de los siglos la legislación cambiara, se superpusiera y se contradijera parcialmente, por lo cual hoy resulta imposible contestar a esta pregunta. Sweeney reflexiona que la omisión de Ajab dé las razones esgrimidas por Nabot para no venderle, y sugiere que esta es "irrelevante para Ajab o para Jezabel. Su omisión marca sutilmente el rechazo de la torá mosaica como base para la vida social israelita. La respuesta de Jezabel enfatiza ese rechazo" 30 .

${ }^{28}$ Según Magdalene, 221, en el antiguo Oriente cómplices, colaboradores/as y beneficiados/as de un robo recibían la misma pena que el/la autor/a principal.

29 MAgdalene, 204-205, refiriéndose a estudios previos sistematizados por CRONAUER, 211-217. Según MAGDALENE, 205-207, no era raro comprar y vender tierra en el antiguo Oriente, a pesar de la reserva de muchos de sus poseedores y de la visión bíblica de que pertenece a YHWH.

30 SWEeney, 249. 


\section{Cuadro 2: Lectura estilística de 1 Re 21}

Escena IA: $\boldsymbol{v v} \cdot \boldsymbol{l}$-4a
Escenario: viñedo de Nabot
Personajes: Nabot y Ajab
Estilo: narración rodeando diálogo
Tema: Ajab no logra poseer la viña de Nabot

Escena IB: $v v .4 b-7$

Escenario: habitaciones de Ajab

Personajes: Ajab y Jezabel (Nabot es mencionado)

Estilo: línea narrativa + diálogo

Tema: Jezabel promete darle a Ajab el viñedo

\section{Escena IC: $v v .8-10$}

Escenario: no especificado

Personajes: Jezabel (ancianos, conspiradores, Nabot es mencionado)

Estilo: narración

Tema: se describen detalles de la

conspiración

\section{Escena IC': vv. 11-14}

Escenario: ciudad de Nabot

Personajes: ancianos, conspiradores, Nabot (Jezabel es mencionada)

Estilo: narración

Tema: se ejecuta el plan en sus detalles

Escena IB': v. 15

Escenario: habitaciones de Ajab

Personajes: Jezabel y Ajab (Nabot es

mencionado)

Estilo: línea narrativa + diálogo

Tema: Jezabel cumple su promesa

Escena IA': v. 16

Escenario: viña de Nabot

Personajes: Ajab (Nabot es mencionado)

Estilo: narración

Tema: Ajab logra la posesión de la viña
Escena IIA: vv. 17-19

Personajes: YHWH y Elías

Estilo: monólogo ("La palabra de YHWH vino a Elías")

Tema: YHWH decreta castigo de Ajab

Escena IIB: vv. 20-22

Personajes: Ajab y Elías

Estilo: diálogo (mayormente palabras de Elías a Ajab)

Tema: Elías condena a Ajab

«Escena» IIC: vv. 23-24

Personajes: (Jezabel y casa de Ajab son mencionadas)

Estilo: comentario del narrador

Tema: castigo de Jezabel y la casa de Ajab

«Escena» IIC': vv. 25-26

Personajes: (Jezabel y Ajab son

mencionados)

Estilo: comentario del narrador

Tema: culpa de Jezabel; maldad sin

parangón de Ajab

Escena IIB': v. 27

Personaje: Ajab

Estilo: narración ("Al oír Ajab estas

palabras...”)

Tema: Ajab se arrepiente

Escena IIA': vv. 28-29

Personajes: YнwH y Elías

Estilo: monólogo ("La palabra de YHWH vino a Elías")

Tema: YHWH pospone el castigo de Ajab

31 WALSH, 195-196. 
Creo que Sweeney tiene razón en su apreciación, pues una omisión tan flagrante es indicativa de un desprecio o rechazo a la tradición de la tierra patriarcal. Sin embargo, como señala astutamente Morag Logan, Jezabel solamente sabía aquello que Ajab le contó, es decir, que Nabot se negaba a venderle, sin razón aparente -lo cual justificaría el malhumor y la toma de decisiones reales- ${ }^{32}$.

Anne Marie Kitz muestra que detrás de esta historia hay conocimiento de un procedimiento jurídico practicado en el mundo antiguo, conocido como karşī akālu ${ }^{33}$. Se trata de un protocolo de la intriga política consistente en denunciar a alguien ante una autoridad superior, pero evitando hacerlo directamente. El protocolo de la intriga política funciona porque

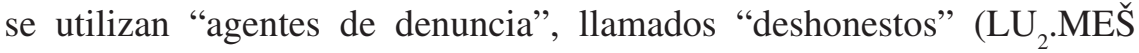
sarāri en la carta ugarítica ARM 10.73 y אנשים בני־בליעל, "varones indignos", en nuestro texto, comparados por ella) ${ }^{34}$. Kitz argumenta que estos dos términos

(1) se refieren a una categoría de gente; (2) su carácter es definido por los adjetivos que los acompañan; (3) son contratados, respondiendo personalmente a sus empleadores(as); (4) funcionan como mensajeros y/o ejecutores de palabras y actos viles; y (5) son responsables de la denuncia pública contra quienes están bajo sospecha de traición ${ }^{35}$.

Además de anclar el evento en las prácticas del antiguo Oriente y no en la imaginación del escritor, el análisis de Kitz aporta otro elemento importante, el de la jerarquía política que actua en diferentes niveles:

32 M. Logan, Gender, Literary Characterization and History: Re-writing the Stories of Deborah and Jezebel. Tesis de doctorado, Princeton 1996, 65-66.

33 Sobre el trasfondo jurídico de este texto, cf. F. I. AnDERSEN, "The Socio-Juridical Background of the Naboth Incident", JBL 85 (1966) 46-57.

${ }^{34}$ La expresión (ה)אנשים בני־בליעל aparece pocas veces en la BHS, dos en nuestro texto (una vez determinada y una vez indeterminada), en Jue 19,22 (אנשי en constructo); 20,13, y en Dt 13,13 [heb.: 14], en un claro contexto polémico: "[...] 'han salido hombres indignos de en medio de ti y han seducido a los habitantes de su ciudad, diciendo: Vamos y sirvamos a otros dioses [a quienes no has conocido]', entonces inquirirás, buscarás y preguntarás con diligencia”. Hay una quinta expresión en que se ha agregado un adjetivo, cortando la cadena del constructo de estos ejemplos: "Se le unieron varones vanos, אנשים רקים בני בליעל [...]" (2 Cr 13,7). Abisag usa

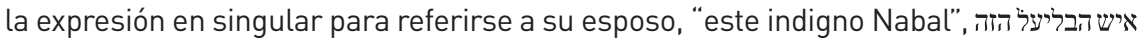
(1 Sam 25,25). Pr 19,28 corrobora su carácter perjudicial para la justicia: “El testigo infame [עד בליעל] se burla del derecho, y la boca de los malvados devora la iniquidad". Más de la mitad de las apariciones están en la HDtr, y de entre estas, diez en los libros de Samuel. (542).

${ }^{35}$ A. M. KITZ, “Naboth's Vineyard after Mari and Amarna”, JBL 134 (2015) 529-545 
- un jefe tribal (Nabot, sentado a la cabeza de los ancianos y nobles),

- un superior inmediato segundo (la tribu de Jezreel),

- un superior inmediato primero (Ajab y/o Jezabel),

- un superior último, YHWH, ante quien son responsables los diferentes subalternos.

En este esquema no aparecen los hombres indignos, puesto que no son autoridad, sino contratados para acusar en representación de sus superiores. Es decir, que Jezabel, autoridad superior primera con Ajab, paga los servicios de los varones indignos, de quienes posiblemente recibiera también el informe de que su trabajo estaba hecho -el sujeto está implícito de los vv. 14-15-; además, el último sujeto mencionado en el v. 13 son los indignos, no los nobles de Jezreel -traicionando a su superior inmediato, YHWH, bajo cuya autoridad están-. El análisis de Kitz demuestra que la traición no es a Nabot en primer lugar, sino YHWH a YHWH, por lo cual la presencia de Elías en los vv. 17-29 no es extraña al relato ${ }^{36}$. Desde otra perspectiva, F. Rachel Magdalene también corrobora que, en última instancia, concierne a la divinidad asegurar justicia en casos de abuso por parte de quienes representan la autoridad humana máxima ${ }^{37}$.

Así, el hallazgo de Kitz y el análisis de Magdalene corroboran el análisis estilístico de Walsh (en el sentido de que todo el capítulo forma una unidad literaria), al que ahora es necesario retornar. Walsh muestra que el centro de la segunda parte (II.C y II.C') está en los vv. 23-24 y 25-26, donde se elabora sobre el castigo a Jezabel y a la casa de Ajab. Suelen considerarse (así como el v. 10, perteneciente a I.C) un agregado posterior (parte de la reelaboración del anuncio de Elías del castigo a Ajab y toda su casa), pero tienen sentido desde una mirada estructural:

Las unidades centrales de cada parte amplían el foco de la historia involucrando a otros/as en los eventos: las escenas IC y IC' implican a los ancianos de Jezreel en la culpabilidad de la reina; la 'escena' IIC implica a toda la casa de Ajab en su castigo. [...] Las escenas IC y IC' reciben aún mayor énfasis con la repetición verbal inusualmente extensa [...] Las escenas IIC y

36 Ib., 536-537, sobre la cuádruple jerarquía; 543-545, sobre el papel de YHWH como superior último, poniendo límites a su superior inmediato ${ }^{1}$ (Ajab), pero dándole una nueva oportunidad después de aclarada la traición. NA'AMAN, 203, n. 3, cita el informe de un caso de juicio por sacrilegio y traición, con pena de muerte y confiscación de tierras del acusado (un terrateniente), llevado a cabo personalmente por Nabucodonosor II (MAGDALENE, 218, n. 194, se refiere a otros dos trabajos sobre este mismo documento).

37 Magdalene, 167-245, estudia en 1 Re 20-22 y 2 Re 9-10 cómo el Consejo divino trata el abuso de autoridad por parte de la realeza en diversas fuentes del antiguo Oriente y bíblicas. 
IIC' llaman la atención por su carácter editorial intrusivo y por sus complejidades y ambigüedades sintácticas ${ }^{38}$.

Aquí percibimos una complementación de los análisis diacrónicos y sincrónicos, por cuanto los versículos más cuestionados “diluyen” la culpa de Jezabel involucrando a la clase política y terrateniente de Israel en la parte I y a toda la casa de Ajab en la parte II. La combinación de métodos arroja mejores resultados que la elección de uno solo de ellos. Al comparar los tres métodos usados por él, Walsh concluye:

Hay diferencias llamativas aun en elementos que cada método considera significativos. Por ejemplo, a pesar de la perogrullada de que una sola obra literaria puede tener un solo protagonista, cada método que usamos señala a un personaje principal en la parte I. El análisis estilístico se centra en Jezabel. Es central en dos sentidos: aparece en una escena central y su acción es la que suministra el impulso de la trama. El análisis sintagmático se centra en Nabot. Su nombre ocurre primero y más a menudo en la parte I y su destino es el que es alterado más radicalmente en el curso de la narración. El análisis paradigmático apunta a Ajab como un protagonista más sutil. Su deseo motiva la historia y su voluntad está por detrás de las iniciativas, hasta las de Jezabel ${ }^{39}$.

Esta percepción de Walsh explica, según mi criterio, por qué la historia tiene tantas aristas diferentes y ofrece tantas lecturas, como si cada una balanceara las otras en un equilibrio dinámico e hiciera imposible identificar a un personaje principal: ¿es Ajab el protagonista? Podría serlo, pero verlo acostado, sin comer y malhumorado da una idea de un rey pasivo antes que protagonista de un hecho que, a los ojos de la reina y del profeta, corresponde a un rey. ¿Es Jezabel la protagonista? $\mathrm{Su}$ papel en el desarrollo de la trama parece indicarlo; sin embargo, la acusación de Elías la menciona muy tangencialmente, indicando que el enojo divino está dirigido primero hacia Ajab. ¿Es Nabot el protagonista? Se lo nombra a menudo, pero luego de su brusco rechazo a Ajab pierde la palabra y la agencia. Si nos hacemos la misma pregunta con respecto a Elías, nos llama la atención primero que aparezca solamente al final y con un papel acartonado, poco real. En suma, es una narración de hilos muy bien entretejidos para no hacer caer todo el peso sobre ninguno de sus personajes.

38 WALSH, 197. El uso de comillas para la escena II.C se debe a que se trata más de un paréntesis del narrador ( $p$, e., falta localización espacial o setting, falta diálogo, desarrollo de acciones, etc.).

39 WALSH, 210. 


\section{Una lectura sociopolítica de nuestro (con)texto}

Nuestra revisión del material existente no puede ignorar a uno de los pocos autores que ofrece una lectura en castellano, Profetas, reyes y hacendados, ya citado ${ }^{40}$. Aunque ya tiene unos años de antigüedad, es un análisis muy valioso, pues va a contracorriente, está bien fundamentado y ofrece elementos de peso que considerar. Yafé arguye que Nabot incurrió en el crimen de ofensa pública del rey y, por tanto, su juicio público y su condena están justificados. Él reconoce que esta lectura es difícil de sostener, dada la popularidad de la condena a Ajab y a Jezabel (en el mismo texto y en toda la tradición posterior); todo lo que reclama es la posibilidad de una lectura diferente, sugerida por el mismo texto. Para él, hay muchas posibilidades de que Ajab y Nabot fueran parientes; esto explicaría tanto la oferta de Ajab de comprarle su viñedo como su actitud no agresiva hacia Nabot ante la negativa de quien no era solamente un súbdito, sino familia, y su duelo por la muerte de este (visto, desde esta perspectiva, como un duelo honesto y sincero, sin hipocresía) ${ }^{41}$. Yafé hace un gran trabajo en mostrar que la dinastía omrida logró desarrollar el Estado, incluyendo la construcción de Samaría (2 Re 16,24) por parte de Omrí y la devolución de territorios conquistados por Omrí por parte de Ajab, con la consiguiente paz con prosperidad con la región. Este desarrollo del reino del Norte necesitó de nuevos aliados, así que Ajab promovió el surgimiento de un nuevo estrato social:

Es posible que la nueva prosperidad solo llegara a ciertos sectores dentro de la población general: a aquellos que estaban cerca del rey y se vieron envueltos en sus proyectos. Esa gente, entre la que se encontraban comerciantes y artistas, constituían una clase de noveau riche. [...]

A medida que se desarrollaban los cambios aumentaban las diferencias entre los noveau riche y el resto de la población urbana. [...] Esta atmósfera de

40 Dado que es la versión en castellano de su tesis doctoral, es imposible resumirla en estas páginas.

41 YAFÉ, 293-294. Yafé también hace un "expediente" de la conducta de Ajab para con sus súbditos, para con los poderes vecinos y para con los profetas de YHWH. Este expediente muestra que Ajab tendió a políticas de cooperación y diálogo antes que a abusar del poder conferido (23-109, esp. 82-89, 93-96). NA'AMAN, 210-211, coincide en que, para construir Samaría, Omrí adquirió el terreno que poseía Sémer, quien era de su mismo clan, Isacar, y que de igual manera "el territorio de Jezreel también fue adquirido de sus dueños anteriores; y que la historia de Nabot refleja un incidente en el curso de la negociación que precedió a la transacción". El autor propone la construcción de Jezreel en la primera mitad del siglo Ix a.e.c. por Omrí y su destrucción por Jazael de Damasco hacia el 830 (214). 
cambio socioeconómico que incluía factores religiosos contribuyó de forma importante al proceso de polarización que estaba teniendo lugar en la sociedad israelita. En el nivel nacional ocurrirían choques debido a que la nueva ciudad centralizaba una economía que había sido aceptada en el país y no coincidía siempre con las prácticas de las comunidades más viejas, las que estaban orientadas tradicionalmente a prácticas pastoriles ${ }^{42}$.

Tenemos varios testimonios bíblicos de la tensión entre los modelos monárquico y tribal en Israel. El más conocido es la advertencia de Samuel/ YHWH en los inicios mismos de la monarquía (1 Sam 8); pero también hay allí mismo descontento con jueces (en ese caso, Samuel) que colocan a sus hijos como sucesores suyos. Hay otros testimonios, como afirmaciones despectivas sobre quienes -desde la clase alta- se percibe como advenedizos: Nabal caracteriza a David y sus muchachos como "muchos siervos hoy día que huyen de su señor" (1 Sam 25,10). Y la misma esposa de David, que en otro momento lo había salvado de Saúl, lo desprecia por haber bailado semidesnudo "ante los ojos de las criadas de sus siervos, como se descubriría sin decoro un insensato" (2 Sam 6,20-23).

La reacción a los cambios sociopolíticos tuvo también, como nota Yafé, un componente religioso, encabezado por un movimiento profético reaccionario a la prosperidad de la ciudad (las "camas de marfil" y las vacas de Basán de Am 3,15; 4,1; 6:4); a la inclinación de la familia real y su séquito al baalismo (que percibirían como idolatría e infidelidad contra YHWH, particularmente bajo Elías y Eliseo) y seguramente también a la adopción de costumbres, alimentos y otros elementos culturales de naciones vecinas. En suma, hay suficientes indicios textuales en el ciclo de Elías y en otros textos para encontrar convincente la lectura de Yafé. Esto significa, para nuestra apreciación de 1 Re 21, que hay que reevaluar las figuras de Ajab y sobre todo de Jezabel, atemperando las acusaciones de abuso de autoridad y corrupción para percibir sus acciones, al menos, como legales.

\section{Sin conclusión}

El abanico de lecturas de la historia de 1 Res 21 que he presentado es tan amplio que prácticamente los extremos se superponen. La mayoría de las lecturas condenan a Ajab y a Jezabel con distintos argumentos, desde los legales hasta los narrativos, con diversos grados de severidad. La lec-

42 YAFÉ, 43-44. LEE, “Königsbücher”, 140, está entre las pocas voces que acusan al movimiento profético de haber producido -no solamente apoyado- el golpe de Estado jehuita. 
tura de Yafé sobresale porque, siendo sociopolítica, defiende a Ajab y Jezabel por sobre Nabot (y eventualmente Elías), por estar en juego dos modelos socio-económicos, políticos, culturales y religiosos que, si no eran incompatibles, al menos se miraban mutuamente con rencor. El surgimiento de una clase alta nueva, ligada a los cambios de gobierno israelita y no al modelo tradicional tribal, produjo rencores y desconfianza (como se ve también en las palabras de Nabal ante el pedido de "subsidios" de David y su banda).

La lectura de Magdalene condena a Ajab (tanto como a Jezabel), sea por inacción frente a un plan quizá hasta manipulado por él, sea por beneficio económico del abuso de poder real. Y la lectura de Kitz ayuda a entender los mecanismos utilizados, sin por eso justificarlos.

Que varios de estos mecanismos fueran legales (incluido el caso, posible, de un juicio sumario por ofensa al rey y a Dios, que llevase a la pena de muerte del reo y su descendencia masculina y a la expropiación de su tierra) no significa que fueran justos; ni siquiera exentos de tensión. No solamente varias voces proféticas desde por lo menos el primer milenio antes de nuestra era, sino también las noticias diarias nos dicen que no siempre lo legal es lo justo, al menos para los sectores más débiles de la sociedad (aunque en nuestra historia se trata de la opresión sobre un súbdito, y solo en ese sentido se podría hablar de Nabot como "débil").

Titulé esta última sección "Sin conclusión” por dos razones. La primera es que he optado por no tomar posición a favor o en contra de Ajab, Jezabel o Nabot. La historia como la tenemos hoy, incluyendo las palabras de YHWH y las de Elías, el marco más amplio señalado por Magdalene del capítulo 20 y el ciclo de Elías nos ofrecen una perspectiva rica y diversa. La palabra final es, por supuesto, la de YHWH, de condena del abuso de poder, ejecutado por varios verdugos, desde la flecha de Jehú y los eunucos que tiran a Jezabel por la ventana hasta "accidentes" como la caída de una ventana de Ocozías en el capítulo 22 o la ejecución del resto de los hijos de Ajab narrada en 2 Re 10. Sin embargo, la palabra final de YHWH se entremezcla con la palabra final de los editores Dtr de la Biblia. Esta constatación es una conclusión, claro, pero es una que nos deja con ganas de volver en busca de otras pistas y así optar por no concluir el estudio. Esta es la segunda razón para elegir el título de la conclusión sin conclusión.

En este trabajo no he tomado a Jezabel como hilo conductor, sino que me he limitado, hasta donde fue posible, a la parábola de la viña de Nabot, donde se pueden encontrar elementos atenuantes de su culpa (como la manipulación de su esposo o la posibilidad de la legalidad de sus acciones), pero en último caso, a la hora de no concluir hay que estar alerta ante cualquier forma de abuso de poder. El sistema patriarcal nos utiliza a cada 
una/o en roles diferentes y nos hace desear ser "el rey". Por otra parte, si bien vivimos en sociedades de régimen democrático y en un continente que ha elegido varias veces a una mujer como presidente de su país, no estamos aún en sociedades igualitarias en términos de género (ni de clase). Esta constatación debe movernos a mayor reflexión, crítica y autocrítica de nuestras presuposiciones sobre el poder (su buen uso y su abuso) y sobre los mandatos de género relacionados con el mismo.

Una cosa, empero, es clara, y es que Jezabel ejerció una dosis importante de poder real, con sello prestado, sustraído o propio ${ }^{43}$. Su (ab)uso de poder se puede leer con muchas lentes distintas, desde la lente Dtr, que la culpabiliza y la detesta, hasta una lente feminista, que busca desenmascarar "sexo e idolatría, metáforas que legitiman la muerte de extranjeras", para tomar prestado de Maricel Mena López; pasando por otras lentes que arrojen otros colores del prisma.

He intentado ofrecer, desde mi perspectiva latinoamericana, feminista y luterana, una variedad de lecturas de un texto que merece consideración por sus múltiples personajes, tensiones de poder, elementos políticos, jurídicos, religiosos y de género, y por su actualidad, al menos en nuestro continente. La invitación a no concluir es una invitación a continuar en diálogo.

\section{Obras consultadas}

Ackerman, S., "The Queen Mother and the Cult in Ancient Israel", JBL 112 (1993) 385-401.

Andersen, F. I., "The Socio-Juridical Background of the Naboth Incident", JBL 85 (1966) 46-57.

Aschkenasy, N., Woman at the Window: Biblical Tales of Oppression and Escape, Detroit 1998.

Ben-BaraK, Z., "The Status and Right of the Gěbîrâ", JBL 110 (1991) 23-34.

Camp, Cl., "1 and 2 Kings", en C. A. Newsom - Sh. H. Ringe (eds.), The Women's Bible Commentary, Louisville 1992, 96-109.

Cronauer, P. T., The Stories about Naboth the Jezreelite. A Source, Composition, and Redaction Investigation of 1 Kings 21 and Passages in 2 Kings 9, New York 2005.

43 Everhart, 690, n. 5, discute la posibilidad de que un sello desenterrado perteneciera a Jezabel, citando a M. C. A. Korpel, "Fit for a Queen: Jezebel's Royal Seal", BARev 34 (2008) 32-37, y la nota del editor, "Is it Tenable?", en el mismo número, 38-39; y a N. AvigAD, “The Seal of Jezebel”, IEJ 14 (1964) 274-276. 
De Vries, S. J., 1 Kings (Word Biblical Commentary), Waco 1985.

Everhard, J., “Jezebel: Framed by Eunuchs?”, CBQ 72 (2010) 688-698.

FERris BeACH, E., "The Samaria Ivories, Marzeah, and Biblical Text”, BA 52 (1993) 94-104.

FinkelsteIn, I., The Forgotten Kingdom: The Archaeology and History of Northern Israel, Atlanta 2013.

Howe Gaines, J., “How Bad Was Jezebel?”, Bible History Daily (junio 2010), http://www.biblicalarchaeology.org/daily/people-cultures-in-the-bible/peoplein-the-bible/how-bad-was-jezebel/ [consulta: 20/3/2016].

Jost, R., "Isebel", accesible en https://www.bibelwissenschaft.de/wibilex/das-bibellexikon/lexikon/sachwort/anzeigen/details/isebel-1/ch/9059fc253174a2743 6f7b3b79d34cb73/ [consulta: 20/3/16].

KITZ, A. M., "Naboth's Vineyard after Mari and Amarna”, JBL 134 (2015) 529-545.

LeE, K. S., "1 and 2 Kings", en D. Patte et al. (eds.), Global Bible Commentary, Nashville 2004, 105-119.

- "Die Königsbücher. Frauen-Bilder ohne Frauen-Wirklichkeit", en L. SCHOTTROFF - M.-Th. WACKER (eds.), Kompendium Feministische Bibelauslegung, Gütersloh ${ }^{2} 1999$, 130-145.

Levoratti, A. J., “La lectura 'política' de la Biblia”, Teología XXIII, 48 (1986) $5-43$.

Logan, M., Gender, Literary Characterization and History: Re-writing the Stories of Deborah and Jezebel. Tesis de doctorado, Princeton 1996.

Magdalene, F. R., "Trying the Crime of Abuse of Royal Authority in the Divine Courtroom and the Incident of Naboth's Vineyard", en A. MERMELSTEIN - Sh. Holtz (eds.), The Divine Courtroom in Comparative Perspective, Leiden 2014, 167-245.

Mena López, M., "Comerán los perros la carne de Jezabel: sexo e idolatría, metáforas que legitiman la muerte de extranjeros", RIBLA 41 (2002) 58-63.

NA' AmAn, N., "Naboth's Vineyard and the Foundation of Jezreel”, JSOT 33 (2008) 197-218.

PARKER, J. F., “'Queens' and Other Female Characters: Feminist Interpretations of First and Second Kings", en S. ScHOLz (ed.), Feminist Interpretation of the Hebrew Bible in Retrospect, I: Biblical Books (Recent Research in Biblical Studies 5), Sheffield 2013, 135-149.

Person, R. F., Jr., recensión de P. T. Cronauer, The Stories about Naboth the Jezreelite, en CBQ 68 (2006) 726-727.

Pruin, D., "What Is in a Text? Searching for Jezebel", en L. L. GrabBe (ed.), Ahab Agonistes: The Rise and Fall of the Omri Dynasty, London 2007, 208235.

Pyper, H. S., recensión de P. T. Cronauer, The Stories about Naboth the Jezreelite, en JSOT 30.5 (2006) 66-67.

RofÉ, A., "The Vineyard of Naboth: The Origin and Message of the Story", VT 38 (1988) 89-104. 
SweEney, M. A., I \& II Kings (Old Testament Library), Louisville 2007.

TrIBLE, Ph., "Exegesis for Storytellers and Other Strangers", JBL 114 (1995) 3-19.

Walsh, J. T., "Methods and meanings: Multiple studies of 1 Kings 21", JBL 111 (1992) 193-211.

Wells, S., "Naboth's vineyard, and God's justice: Forgiving Ahab", Christian Century 17/4 (2013) 32-34.

Williamson, H. G. M., recensión de P. T. Cronauer, The Stories about Naboth the Jezreelite, en VT 57 (2007) 127.

WyATT, St., "Jezebel, Elijah, and the Widow of Zarephath: A ménage-à-trois that Estranges the Holy and Makes the Holy the Strange", JSOT 36 (2012) 435-458.

Yafé, F. C., Profetas, reyes y hacendados. Estudio teológico-sociológico y crítico del Israel preclásico, Buenos Aires 1997.

ZlotniK, H., "From Jezabel to Esther: Fashioning Images of Queenship in the Hebrew Bible", Biblica 82 (2001) 477-495; acesible en: http://www.bsw.org/biblica/vol-82-2001/from-jezebel-to-esther-fashioning-images-of-queenship-inthe-hebrew-bible/271/article-p479.html [consulta: 20/3/16].

Mercedes L. García Bachmann 